\title{
Exploiting supramolecular interactions to produce bevacizumab-loaded nanoparticles for potential mucosal delivery
}

\author{
Leonardo M.B. Ferreira ${ }^{\mathrm{a}}$, Jovan D. Alonso ${ }^{\mathrm{b}}$, Charlene P. Kiill ${ }^{\mathrm{a}}$, Natália N. Ferreira ${ }^{\mathrm{a}}$, \\ Hilde H. Buzzác, Denis R. Martins de Godoi ${ }^{\mathrm{b}}$, Douglas de Britto ${ }^{\mathrm{d}}$, Odilio Benedito G. Assis ${ }^{\mathrm{e}}$, \\ Thiago V. Seraphim ${ }^{\mathrm{f}}$, Júlio César Borges ${ }^{\mathrm{f}}$, Maria Palmira D. Gremião ${ }^{\mathrm{a}, *}$ \\ a School of Pharmaceutical Science, São Paulo State University, UNESP, Rodovia Araraquara/Jaú Km 1, Araraquara, São Paulo, Brazil \\ ${ }^{\mathrm{b}}$ Institute of Chemistry of Araraquara, São Paulo State University, UNESP, Araraquara, São Paulo, Brazil \\ ${ }^{\mathrm{c}}$ Biophotonics Laboratory, São Carlos Institute of Physics, University of São Paulo (USP), São Carlos, São Paulo, Brazil \\ ' EMBRAPA, Semi-Arid, Rodovia BE-428, Km 152, P.O. Box 23, Petrolina, PE, Brazil \\ EMBRAPA Instrumentation, Rua XV de Novembro, 1.452, P.O. Box 741, 13560-970 São Carlos, SP, Brazil \\ ${ }^{\mathrm{f}}$ Institute of Chemistry of São Carlos, University of São Paulo, USP, São Carlos, Brazil
}

\section{A R T I C L E I N F O}

\section{Keywords:}

Bevacizumab

Supramolecular interactions

Polymeric nanoparticles

Drug delivery platform

Mucoadhesion

Mucus penetration

\begin{abstract}
A B S T R A C T
Monoclonal antibody (mAb) delivery is gaining importance for local, systemic, and route-specific targeting. The mucus constitutes the main barrier for this type of delivery. In the present study, we aimed to develop a drug delivery platform by integrating mucus penetrating and mucoadhesive agents into a single system. Our hypothesis is that by combining these opposing functions, this system could have its properties modulated according to specific purposes. Self-assembly studies were conducted using three classes of building blocks: the protein drug bevacizumab (BVZ), mucus-penetrating polyanion dextran sulfate (DS), mucoadhesive polycations trimethylchitosan (TMC) and chitosan oligosaccharides (COS). We obtained two types of nanoparticles by manipulating supramolecular interactions between the components. Binary protein-polyanion (BVZ/DS) nanoparticles showed size of approximately $150 \mathrm{~nm}$ and a negative zeta potential. Ternary protein-polyanion-polycation (BVZ/DS/COS) nanoparticles were obtained using COS and exhibited $350 \mathrm{~nm}$ and a positive zeta potential. Assisted by calorimetric information, we demonstrated that building stable ternary nanoparticles carrying positive charges were not possible using the polycation TMC due to its thermodynamic constraints. Furthermore, spectroscopy analysis and CAM assay indicated that BVZ continued structurally and functionally stable after its incorporation into the nanoparticles. These two types of nanoparticles exhibited different behaviors when interacting with mucin, as shown by DLS and AFM studies. While the negatively charged particles promoted dispersion of the mucin network, suggesting a mucus penetrating effect of DS, the positively charged particles formed aggregates, probably caused by the mucoadhesive effect of COS. These results highlight the importance of understanding the role of supramolecular interactions, responsible for forming drug delivery systems containing complex molecules, such as proteins and polymers.
\end{abstract}

\section{Introduction}

Drug therapy using monoclonal antibodies (mAbs) promises to boost the pharmaceutical market in coming years $[1,2]$. These biomacromolecules exhibit a broad therapeutic capacity for treating several types of highly complex diseases. Currently, mAb therapies have been used to treat autoimmune diseases, rheumatoid arthritis, Chron's disease, as well as several types of cancers [3-6]. Although injectable administration (i.e. intravenous and subcutaneous) is the most common way to deliver the mAbs, there is an increasing effort on the part of scientists, who study drug delivery, to establish alternative routes of administration attempting to bypass particular problems associated to parenteral routes. Pulmonary and nasal routes, for example, have been investigated with this purpose [7-10]. However, although these are non-invasive routes, both contain mucus, a barrier which hinders the delivery of high molecular weight drugs.

Bevacizumab (BVZ) is a mAb that exhibits anti-angiogenic activity by blocking the vascular endothelial growth factor (VEGF-A), which is the main factor responsible for blood vessel development [11]. Recently, BVZ mucosal delivery for local therapy in the eye and nose has

\footnotetext{
* Corresponding author at: School of Pharmaceutical Science, São Paulo State University, UNESP, Rodovia Araraquara-Jaú Km 01, Araraquara, SP 14801-902, Brazil.

E-mail address: pgremiao@fcfar.unesp.br (M.P.D. Gremião).
} 

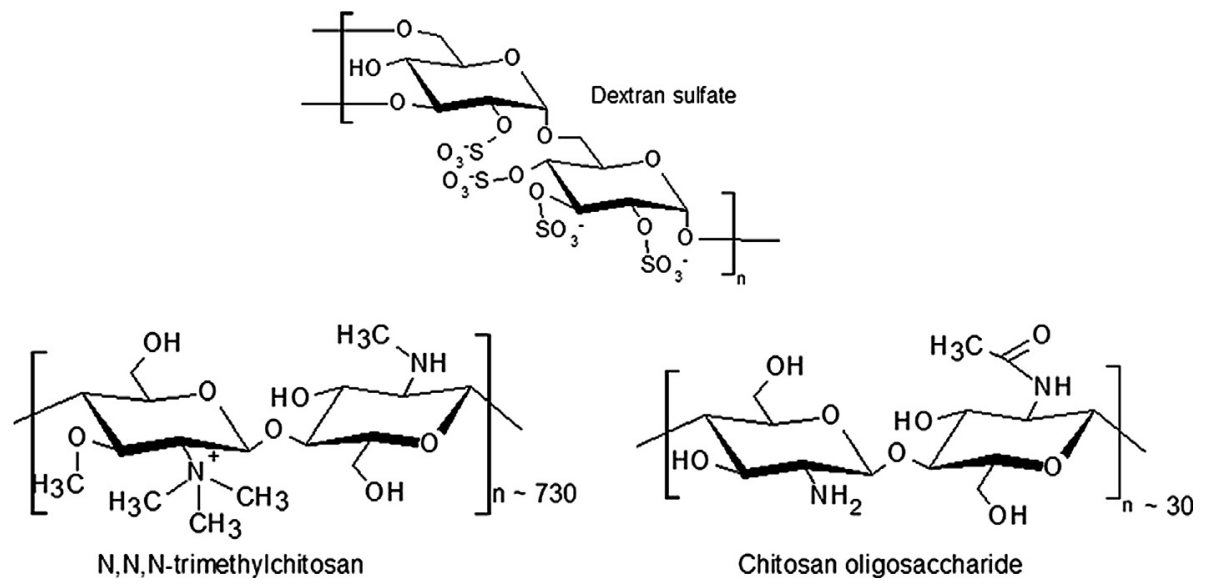

Fig. 1. Chemical structures of excipients used to prepare polymeric nanoparticles.

been investigated for treating macular degeneration and hereditary hemorrhagic telangiectasia, respectively [12-14]. Furthermore, BVZ mucosal delivery should be explored in other sites of action, such as systemic activity and specific routes (i.e. nose-to-brain or pulmonary). Since mucus is the common denominator in these cases, the rational design of a delivery system should properly select building blocks and envision alternatives to modulate system properties that interact with mucus or that enable transportation through the mucus. In this context, mucoadhesion and mucopenetration have been investigated as two opposite approaches for delivering nanoparticulate systems through mucosal routes $[15,16]$. However, recent findings suggest that integrated strategies are better suited to establish more control over the interaction site and mucus clearance function [17-19].

Supramolecular interactions are non-covalent forces responsible for forming nanostructured systems and biointerfacial interactions upon administration [20]. For example, structure, properties, and dynamics of polyelectrolyte complexation, as well as mucus (as represented by mucin-mucin interactions), and mucus/carrier interfaces, are all dependent on the action of non-covalent forces throughout all scales of analysis [21-23]. Therefore, understanding and correctly manipulating those interactions might be key to achieving a rational design for mucosal drug delivery systems. Herein, this approach was explored to develop polymeric nanoparticles for BVZ mucosal delivery.

Like other biomacromolecules, BVZ has a series of limitations regarding formulation development. Their physical instability may be associated with two major pathways-denaturation or aggregation, since they might denature or aggregate under a variety of conditions, such as temperature change, shear, processing steps, protein concentration change, viscosity, ionic strength and $\mathrm{pH}$. Thus, these factors should be considered for develop drug delivery systems [24]. Therefore, the study of BVZ/carrier interactions is mandatory to maintain the tridimensional integrity of the drug.

Mucoadhesion is a complex phenomenon which occurs when several different mechanisms are combined. Generally, different materials and systems are able to establish supramolecular interactions with mucosal components, such as mucin chains, because of the presence of reactive functional groups at the polymer chains, which facilitate adhesion to the mucus. On the other hand, to design mucus penetrating systems, the opposite logic must be used in order to open paths, facilitating system permeation [19,25-27].

Some studies have reported that the polyanion dextran sulfate (DS), and the polycations trimethylchitosan (TMC) and chitosan oligossacharides (COS) have mucus penetranting and mucoadhesive properties, respectively [28-31]. Since the BVZ protein is positively charged under its $\mathrm{pI} \sim 8.3$, we hypothesized that a drug delivery system could be engineered by manipulating the electrostatic interactions among these three classes of building blocks. The key idea was to produce a platform whose penetrating/adhesive properties might be altered by adding/removing the proper building block. In the present study, we demonstrated that the manipulation of supramolecular interactions is pivotal during the decision-making steps of nanoparticle development, aimed at unifying mucus penetrating and mucoadhesive strategies in a single drug delivery platform.

With this purpose in mind, we first studied the assembly of building blocks (DS, TMC, COS and BVZ), which exhibit different charges at the working $\mathrm{pH}$ value (6.2), for system development; thereafter, BVZ structural features in nanoparticles were evaluated to ensure the drug performance. Interaction behavior between mucin and developed nanoparticulate systems were assessed using DLS and AFM techniques. Lastly, the CAM model was used to measure the anti-angiogenic effects of developed nanoparticles.

\section{Experimental section}

\subsection{Materials and stock solutions}

Dextran sulfate (DS, Mw $=500 \mathrm{kDa}$ ) was purchased from SigmaAldrich (Brazil), while Avastin ${ }^{\circledR}$ (Bevacizumab injection $25 \mathrm{mg} / \mathrm{mL}$, Roche Pharma Ltd., Switzerland) was purchased from Genentech (USA). The quaternized chitosan, trimethylchitosan (TMC), was obtained through the methylation reaction with dimethyl sulfate [32]. The final product was characterized, and the determined molecular weight was $117 \mathrm{kDa}$. Chitosan oligosaccharides (COS, Mw $=5 \mathrm{kDa}$ ) were purchased from Sigma-Aldrich (Brazil). Stock solutions of DS ( $\left.2 \mathrm{mg} \mathrm{mL}^{-1}\right)$, BVZ (2.5 $\left.\mathrm{mg} \mathrm{mL}^{-1}\right)$, TMC $\left(1.2 \mathrm{mg} \mathrm{mL}^{-1}\right)$, and COS $\left(1.2 \mathrm{mg} \mathrm{mL}^{-1}\right)$ were prepared by solubilizing polyanion, polycation, and protein in a suitable amount of Milli-Q water or Phosphate-buffered saline PBS ( $5 \mathrm{mM}, \mathrm{pH}$ 6.2). Chemical structures of the used excipients can be seen in Fig. 1.

\subsection{Methods}

\subsubsection{Preparation of binary protein-polyanion nanoparticles}

The formation of BVZ/DS nanoparticles occurs by simply mixing the polyanion solution with the protein solution in microcentrifuge plastic tubes. Assembly of the particles are driven by electrostatic interactions between the components and, therefore, are subject to physical-chemical factors of the building blocks in solution. We investigated the concentration of the polyanion DS and the theoretical solids content on the colloidal system properties, such as size, polydispersity (PDI), zeta potential, and association efficiency. The influence of the polyanion concentration was evaluated by measuring different solutions, in which the concentration of BVZ was set at $0.5 \mathrm{mg} \mathrm{mL}^{-1}$ and increasing concentrations of DS $\left(0.1,0.2,0.3,0.4,0.5\right.$ and $\left.1.0 \mathrm{mg} \mathrm{mL}^{-1}\right)$ were added. 
The influence of theoretical solids content in the complexation process was evaluated by measuring the different final component concentrations (sum of polyanion and protein mass), while maintaining a fixed mass ratio between components.

\subsubsection{Preparation of ternary protein-polyanion-polycation nanoparticles}

This study consisted of adding increasing concentrations of the polycationic agent (TMC or COS at $0.1,0.2,0.4$ and $0.6 \mathrm{mg} \mathrm{mL}^{-1}$ ) into previously selected BVZ/DS binary nanoparticles. Herein, our goal was to acquire ternary nanoparticle systems with residual positive charge. Association Efficiency (AE\%) results were used to select the best polycation for producing ternary nanoparticles. After defining the best polycation, we evaluated the influence of theoretical solids content (sum of polyanion, polycation and protein mass) on the size, PDI and zeta potential of nanoparticles, maintaining a fixed mass ratio between the components.

\subsubsection{Dynamic light scattering (DLS) and zeta potential ( $\zeta)$}

DLS and Zeta potential measurements (Zetasizer Nano ZS, Malvern Instruments) were conducted to monitor the self-assembly of nanoparticles in terms of size, polydispersity index (PDI), and Zeta potential. All measurements were conducted in triplicate at a temperature of $25 \pm 2{ }^{\circ} \mathrm{C}$. In addition, reported diameter should be understood as an average of the hydrodynamic diameter (Z-average) and is determined by the Stokes-Einstein relation (Eq. (1)). Zeta potentials were determined by electrophoretic mobility $(\mu)$ measurements using the Smoluchowski equation (Eq. (2))

$D h=\frac{K T}{3 \pi \eta D}$

In which $\mathrm{Dh}$ is the hydrodynamic diameter, $\mathrm{K}$ is Boltzman's constant, $\mathrm{T}$ is the absolute temperature, $\eta$ is viscosity and $\mathrm{D}$ is the diffusion coefficient.

$\zeta=\frac{\mu \eta}{\varepsilon}$

In which $\zeta$ is the zeta potential, $\mu$ is the electrophoretic mobility, $\eta$ is the viscosity of the medium and $\varepsilon$ is the dielectric constant.

\subsubsection{Association efficiency (AE\%)}

Association Efficiency was measured by using the bicinchoninic acid method (Thermo Scientific Pierce BCA Protein Assay). After particle formation, a portion of the formulation was removed and centrifuged (Thermo Scientific) at $15,000 \mathrm{rpm}$, for $1 \mathrm{~h}$. The supernatant was then assayed for protein concentration. This colorimetric method detects the total amount of protein present in the alkaline medium, which is capable of reducing $\mathrm{Cu}^{2+}$ to $\mathrm{Cu}^{1+}$ and results in a purple coloration. The assay was performed in triplicate for each batch. The association efficiency (AE\%) of BVZ to binary and ternary nanoparticles was determined by Eq. (3) through a previously validated analytical standard curve using BVZ stock solution $\left(1 \mathrm{mg} \mathrm{mL}^{-1}\right)$.

$A E(\%)=\frac{\text { Total mass of BVZ added-Total mass of BVZ in the supernatant }}{\text { Total mass of BVZ added }}$

\subsubsection{Isothermal titration calorimetry (ITC)}

ITC experiments were performed in an iTC200 device (GE Healthcare Life Sciences). The polyelectrolytes DS, TMC, and COS and the BVZ protein were extensively dialyzed ( $24 \mathrm{~h}$ ) against the PBS buffer $5.1 \mathrm{mM} \mathrm{pH}$ 6.2. The samples were centrifuged to remove any particulate material. The titrations were performed by filling the ITC cell with the DS solution $(0.0002 \mathrm{mM})$ and the syringe with the polycation solutions COS $(0.2 \mathrm{mM})$, TMC $(0.008 \mathrm{mM})$ or protein BVZ $(0.05 \mathrm{mM})$, at $20^{\circ} \mathrm{C}, 25^{\circ} \mathrm{C}$ and $35^{\circ} \mathrm{C}$. Blank titrations were performed by applying the polycation or protein solution into the cell filled with buffer. Data analysis was conducted on the Origin 7.0 MicroCal iTC200 software. The isotherm was established based on the integration of the obtained peaks by plotting the resulting heat values from each injection against the molar ratio of the samples. In addition, dilution heat was subtracted from the data considering the last points of the ITC experiments, where no significant heat changes were observed. The thermodynamic parameters were determined using the one set of sites model that adjusts the curve by nonlinear regression (method of least squares). The thermodynamic relationships considered for this experiment are described in Eqs. (4)-(6).

$K d=\frac{1}{K a}$

$\Delta G=-R T \ln K a=R T \ln K d$

$\Delta G=\Delta H-T \Delta S$

In which, Kd is the dissociation constant of the system, Ka is the association constant, $\Delta \mathrm{G}$ is the Gibbs free energy change, $\Delta \mathrm{S}$ is the entropy change, $\Delta H$ is the enthalpy change, $R$ is the gas constant and $T$ is the absolute temperature.

\subsubsection{Differential scanning microcalorimetry (Nano-DSC)}

Microcalorimetric scannings were conducted on a Nano-DSC (TA Instruments) at a heating rate equal to $1^{\circ} \mathrm{C} \mathrm{min}^{-1}$ and scan range from 0 to $100{ }^{\circ} \mathrm{C}$. The curves represent the thermal profile of pure BVZ and BVZ loaded in binary and ternary nanoparticles. The buffer used in the preparation of all samples was PBS $5.1 \mathrm{mM} \mathrm{pH} \mathrm{6.2.} \mathrm{The} \mathrm{baseline} \mathrm{cor-}$ rection was performed by subtracting the thermogram obtained from the excipient under identical conditions. The thermograms were then treated using the NanoAnalyze software to obtain the thermodynamic parameters related to the protein unfolding process.

\subsubsection{Investigation of BVZ integrity into developed systems}

2.2.7.1. Circular dichroism spectroscopy $(C D)$. $C D$ measurements were obtained on a J-815 spectropolarimeter (Jasco Inc.). Evaluation of protein-polyanion interactions was conducted by setting the BVZ concentration at $0.5 \mathrm{mg} \mathrm{mL}^{-1}$ and using increasing concentrations of DS. Analysis of pure BVZ at the same concentration was also performed as control. The buffer solution used in the preparation of all samples was PBS $5.1 \mathrm{mM} \mathrm{pH} \mathrm{6.2.} \mathrm{All} \mathrm{acquired} \mathrm{spectra} \mathrm{had} \mathrm{an} \mathrm{average} \mathrm{of} 30$ cumulative scans and the buffer spectrum was subtracted from each sample by treatment with the Origin software. The values obtained were normalized to residual molar ellipticity $([\theta])$ described by Eq. (7)

$[\theta]=\frac{(\theta \times 100 \times M W)}{(c \times l \times n)}$

In which, $\theta$ is the ellipticity in degrees, MW is the molecular weight of the protein $\left(\mathrm{g} \mathrm{mol}^{-1}\right), \mathrm{c}$ is the protein concentration $\left(\mathrm{mg} \mathrm{mL}^{-1}\right), 1$ is the optical path $(\mathrm{cm})$, and $\mathrm{n}$ is the number of amino acid residues. The secondary structure content of the samples containing BVZ was estimated by the CDNN Deconvolution program [33].

2.2.7.2. Fluorescence spectroscopy. Fluorescence measurements were performed in an F-4500 fluorescence spectrophotometer (Hitachi). The spectra were obtained by excitation at $280 \mathrm{~nm}$ and fluorescence emissions was obtained from $300 \mathrm{~nm}$ to $420 \mathrm{~nm}$. Evaluation of proteinpolyanion interaction was performed by setting the BVZ concentration at $0.5 \mathrm{mg} \mathrm{mL}^{-1}$ and using increasing concentrations of DS. A curve containing only BVZ at the same concentration was also obtained to be used as control. The buffer used in the preparation of all samples was PBS $5.1 \mathrm{mM}$ pH 6.2. The intrinsic fluorescence emissions data were analyzed using the wavelength of maximum emission $(\lambda \max )$ and spectral center of mass $(\langle\lambda\rangle)$ described by Eq. (8).

$\langle\lambda\rangle=\frac{\sum F i \lambda i}{\sum F i}$ 


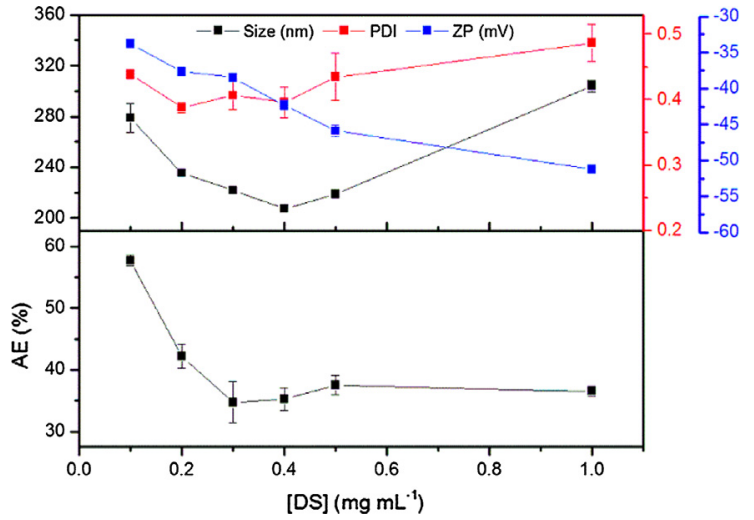

Fig. 2. Influence of polyanion dextran (DS) concentration on the colloidal properties of BVZ/DS nanoparticles: size, polydispersity index (PDI), zeta potential (ZP) and association efficiency (AE\%).

\subsubsection{CAM assay}

Chicken eggs obtained from a local producer (A'doro, São Carlos/ SP, Brazil) were used for the experiments. On the first day of embryo development (ED), eggs were wiped using $70 \%$ alcohol tissue before being placed in an incubator at $37^{\circ} \mathrm{C}$. During ED1 and ED2, the eggs were kept under constant slow rotation - half cycle every $30 \mathrm{~min}$. On ED3, a small hole in the shell was punctured using tweezers and 3-4 mL of albumin was removed with a syringe and the rotation was interrupted. A window of $2 \mathrm{~cm}^{2}$ was opened on the same day and sealed with adhesive tape when they returned to the incubator. Six experimental groups $(\mathrm{n}=3)$ were tested: PBS $5.1 \mathrm{mM} \mathrm{pH} 6.2$ was used as negative control, BVZ (Commercial Avastin, Genentech/Roche, USA) was used as positive control, and DS polymer, DS/COS (nanoparticles without protein), BVZ/DS nanoparticles, and BVZ/DS/COS nanoparticles composed the experimental groups. From ED8 to ED11, $200 \mu \mathrm{L}$ of solution for each group was placed in the CAM. A Teflon ${ }^{\circledR}$ ring with a fixed area $\left(0.95 \mathrm{~cm}^{2}\right)$ was used to contain the solution in the same place. CAM implant pictures were taken over time using a USB Digital Microscope ${ }^{\circledast}$ (AVANTGARDE, China) to observe daily vascular changes. A semiquantitative analysis was performed using the MATLAB $^{\circledR}$ (The MathWorks, USA) algorithm. The green channel of the images was used to enable automatic detection of the vessels because the blood absorbs light in the 500-600 nm spectral region. A convolution of the 8-bit green channel matrix was performed with a disk mask and the radius was adjusted for the best result. This process generates a binary image where the black pixels correspond to the vessels. For each image, the ratio between the area with vessels and total area was calculated. This value was obtained for each image over time and was normalized using the values found on the first day. All procedures were approved by the Institutional Animal Care and Use Committee of the Sao Carlos Institute of Physics (protocol number 08/2016).

\subsubsection{Nanoparticles-mucin interactions}

The interaction behavior between mucin and nanoparticulate systems was evaluated by studying the association of BVZ/DS and BVZ/ DS/COS nanoparticles with the mucin solution using DLS and AFM techniques.

2.2.9.1. Mucin-Particle method using dynamic light scattering (DLS). Stock solution of mucin (MUC) $0.5 \mathrm{mg} \mathrm{mL}^{-1}$ was prepared by dispersing Mucin Type II crude porcine stomach (Sigma), which was then filtered through a $0.45 \mu \mathrm{m}$ membrane. Nanoparticles were added to the mucin dispersion in different concentrations (0-50\%), mixed and maintained for $30 \mathrm{~min}$ at room temperature. All measurements were performed in triplicate and the results are reported as mean and standard deviation.
2.2.9.2. Atomic force microscopy characterization (AFM). Nanoparticles, mucin dispersion, and mucin combined with nanoparticles were diluted in Milli-Q water to a solids content concentration of $2-5 \mu \mathrm{g} \mathrm{mL}^{-1}$. A portion of the samples $(2 \mu \mathrm{L})$ were immediately spread on a pre-cleaved mica surface and maintained in a desiccator $\left(25^{\circ} \mathrm{C}\right)$ for at least $1 \mathrm{~h}$. AFM images on "Tapping Mode" were obtained in an atomic force microscope (AFM Dimension V, Veeco) using a conventional cantilever $0.06 \mathrm{~N} / \mathrm{m}$.

\section{Results and discussion}

\subsection{Polyanion concentration and theoretical solids contents affect colloidal properties of binary BVZ/DS nanoparticles}

Properties of colloidal systems are greatly affected by supramolecular forces [34]. To overcome the drawbacks caused by $\mathrm{pH}$ manipulation, we decided to maintain the $\mathrm{pH}$ level at 6.2, same as the commercial BVZ formulation. As of this starting point, we faced challenges to maintain the BVZ structure, essential for drug performance, and the building blocks assembly, which exhibit different charges at the working $\mathrm{pH}$ value. Association of the stock solution BVZ protein and polyanion DS produced BVZ/DS particulate systems. Notably, DS is a sulfated polysaccharide with a high density of negative charges $(\sim 2.3$ sulfate groups per glucosidic unit, as reported by the manufacturer) at $\mathrm{pH} 6.2$, while $\mathrm{BVZ}(\mathrm{pI}=8.3$ ) carries positive residual charges in the same conditions.

The colloidal properties of BVZ/DS binary nanoparticles depended on the polyanion concentration (Fig. 2). Particle size decreased as DS concentration was increased to $0.4 \mathrm{mg} \mathrm{mL}^{-1}$, resulting in a mass ratio of 1.25:1 (protein:polyanion). Next, nanoparticle size started to increase again. PdI values ranging between 0.4 and 0.5 exhibited a polydisperse system, with the highest values being directly attributed to higher polyanion concentrations. Particulate systems formed by electrostatic interactions, such as polyplexes and lipoplexes, are well described in literature, and commonly exhibit high polydispersity indexes, most likely due to the complex nature of the electrostatic interactions between these macromolecules [35,36].

Zeta potential (ZP) and BVZ association efficiency (AE\%) to binary nanoparticles decreased as the polyanion concentration was increased. This result might be explained by the higher adsorption of DS on the surface of the particles. Furthermore, the decrease in $\mathrm{AE} \%$ appears to be more closely related to the supramolecular interactions mechanisms which occur between polyanions and proteins. The DS conformation in solution depends on concentration, and its hydrodynamic radius decreases significantly as concentration increases, adopting a more compact form [37]. Since the interactions between BVZ and DS are originally driven by electrostatic interactions, we suggest using a compact form of DS, which has less available negative charges to interact with $\mathrm{BVZ}$, therefore, leading to $\mathrm{AE} \%$ reduction.

The evaluation of the binary colloidal system properties in relation to DS concentration led us to select a formulation comprising a protein:polyanion weight ratio of $1.25: 1$ for subsequent studies ([DS] $=0.4 \mathrm{mg} \mathrm{mL}^{-1}$ ). Then, maintaining this proportion, we evaluated how such properties behave in regard to the theoretical solids content, defined as the sum of protein and polyanion mass used to prepare $2 \mathrm{~mL}$ of nanoparticle dispersion (Fig. 3). Size and PDI increased with the increase of total mass used, which is probably due to greater occurrence of supramolecular interactions between the components, since a greater number of molecules are confined in the same volume. Furthermore, decrease in ZP suggests that more DS molecules may be attached to the particle surface. AE\% increased significantly when comparing the $0.45 \mathrm{mg}$ samples with the $0.9 \mathrm{mg}$ and $1.8 \mathrm{mg}$ samples. However, analyzing the highest values of solids content, no significant difference was found. Thus, our results suggest that these interactions reach a saturation limit, which depends on the degree of molecular confinement. 


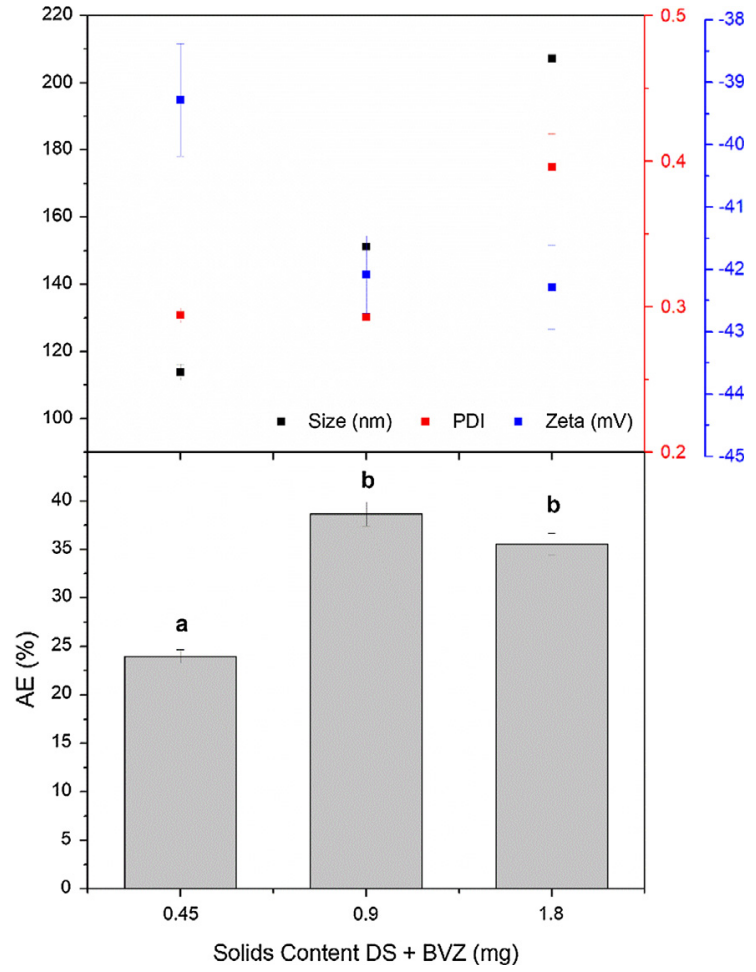

Fig. 3. Influence of solids content on colloidal properties of BVZ/DS nanoparticles: size, polydispersity index (PDI), zeta Potential (ZP) and association efficiency (AE\%). Different letters demonstrate statistically significant differences $(\mathrm{p}<0.05)$.

\subsection{BVZ remains folded when in association with binary DS nanoparticles}

Structural integrity is mandatory to preserve BVZ biological activity. Therefore, spectroscopic studies were performed to access the secondary and tertiary structure of BVZ in BVZ/DS binary nanoparticles. The CD spectrum of BVZ showed secondary structural elements, mostly characterized by $\beta$-sheet conformations (Fig. 4A), and a few differences between the pure protein and BVZ/DS formulations spectra were observed. The spectra deconvolution and secondary structure prediction (Table 1 ) revealed a $\beta$-sheet percentage of around $40 \%$, which is typical for monoclonal antibodies [38,39]. Interestingly, a small positive $C D$ signal at $230 \mathrm{~nm}$, which is related to tertiary structure, was also observed in all conditions, indicating that this BVZ structure level was preserved in the presence of DS [40].

The tertiary structure of BVZ was investigated using intrinsic fluorescence properties of the tryptophan residues, which are numerous (26 residues) in the BVZ molecule. Fig. 4B shows the intrinsic fluorescence spectrum of BVZ compared with BVZ incorporated into binary nanoparticles, and Table 1 shows the values of $\lambda_{\max }$ and $\langle\lambda\rangle$. BVZ exhibited $\lambda_{\max }$ at $333 \mathrm{~nm}$ and $\langle\lambda\rangle$ at $345 \mathrm{~nm}$. BVZ/DS nanoparticles displayed clear suppression in fluorescence intensity and a small red-shift $(\sim 2 \mathrm{~nm})$, suggesting that the electrostatic interaction might partially expose some tryptophan groups to the aqueous media and/or suppress the fluorescence emission of buried tryptophan residues. This increases the contribution of partially exposed tryptophan residues to the final spectrum. The fluorescence absorption spectrum is the average contribution of all tryptophan residues distributed throughout the protein and, since this amino acid is highly present in BVZ, it is impossible to know exactly which one has changed in its environment. Furthermore, despite the changes in the spectra, the averaged tryptophan environment remains the same as observed in the inset normalized graphs.

In summary, spectroscopic data of $\mathrm{CD}$ and fluorescence ensures that BVZ maintained the three-dimensional structure even after being incorporated into binary BVZ/DS nanoparticles. In some formulations,
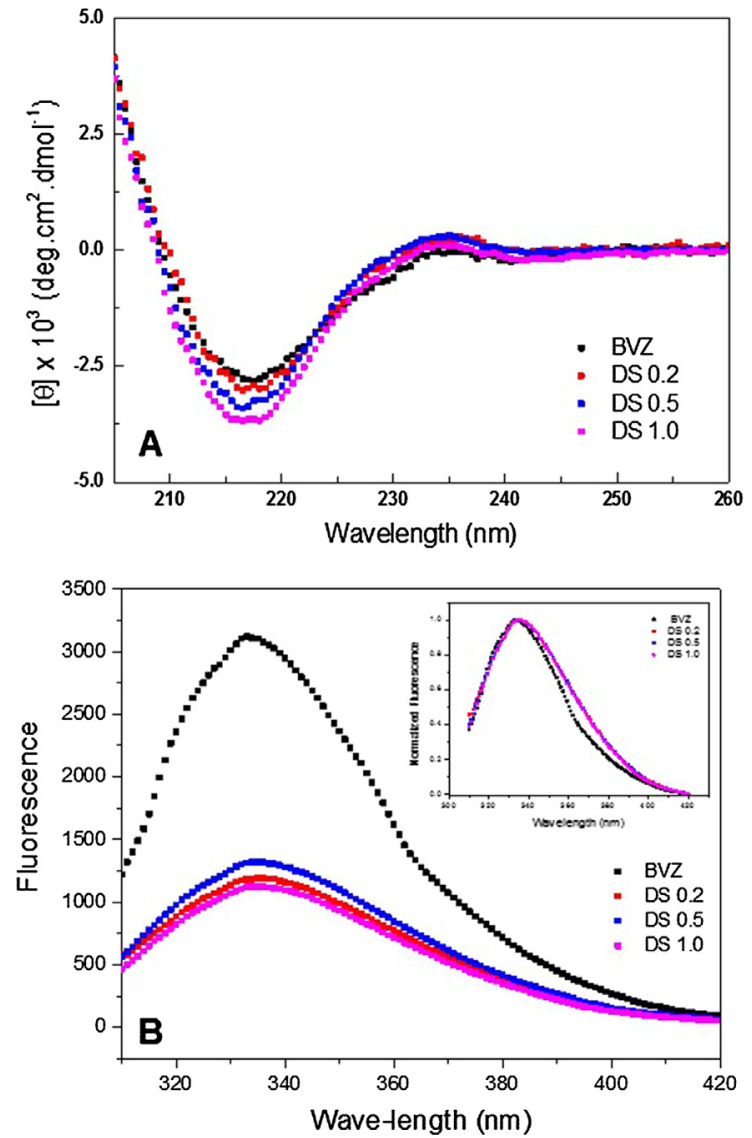

Fig. 4. Spectroscopic analysis of BVZ and BVZ/DS nanoparticles in PBS $5.1 \mathrm{mM}$ $\mathrm{pH}$ 6.2. (A) Circular dichroism spectra and (B) Fluorescence spectra of BVZ/DS systems were obtained as concentrations of polyanion increased.

Table 1

Structural parameters of BVZ incorporated in different binary nanoparticles containing increased DS concentrations.

\begin{tabular}{llllll}
\hline \multirow{2}{*}{ Technique } & Property & \multicolumn{2}{l}{ Formulations } & \\
\cline { 3 - 6 } & & BVZ & DS 0.2 & DS 0.5 & DS 1.0 \\
\hline \multirow{2}{*}{ CD } & $\alpha$-helix (\%) & 5 & 5 & 6 & 6 \\
& $\beta$-sheet (\%) & 47 & 47 & 46 & 45 \\
& $\beta$-turn (\%) & 17 & 17 & 17 & 17 \\
& Random & 35 & 35 & 35 & 35 \\
Fluorescence & $\lambda$ max (nm) & 333 & 335 & 335 & 335 \\
& $\langle\lambda\rangle(\mathrm{nm})$ & 345 & 347 & 347 & 347 \\
\hline
\end{tabular}

slight changes in the secondary structural elements and in the tertiary structure were observed. However, the implications of these changes on the functionality of the protein are unknown and should be further investigated through biological assays.

\subsection{Polycations TMC and COS compete with bevacizumab for DS association to produce ternary nanoparticles}

The systems produced here are built and stabilized by supramolecular forces, of which the majority are of electrostatic nature. Thus, forming ternary particles composed of two molecular entities with the same charge becomes challenging, since they may compete among themselves. Therefore, in order to produce stabilized protein-polyanion-polycation systems, we studied two different types of polycationic agents during the development. Our previous studies regarding colloidal properties of binary BVZ/DS nanoparticles, and structural 


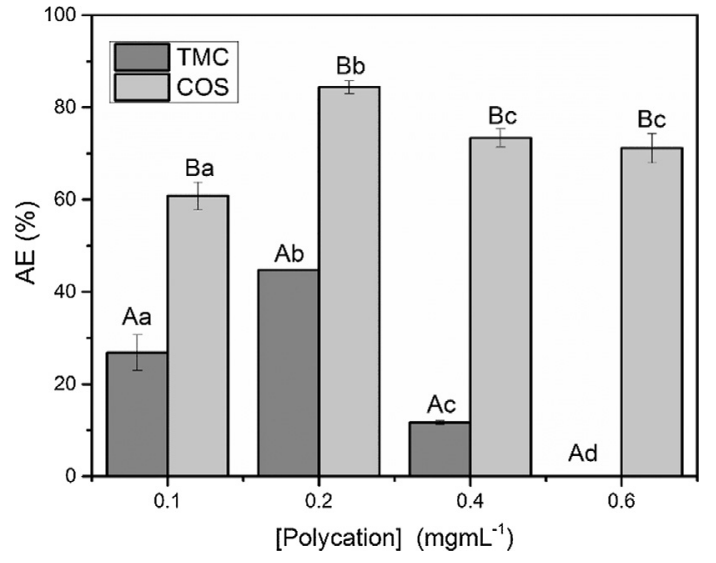

Fig. 5. Influence of polycationic agents on association of BVZ to polyanion DS (mean $\pm \mathrm{SD}, \mathrm{n}=3$ ). Capital letters compare TMC with COS in the same concentration. Lowercase letters compare the same polycationic agent in different concentrations. For reference: $\mathrm{AE} \%$ in binary nanoparticles $=38.6 \%$.

properties of BVZ embedded in these systems, enabled us to select the formulation to produce ternary systems. The chosen BVZ/DS formulation $\left(B V Z=0.25 \mathrm{mg} \mathrm{mL}^{-1}\right.$, $\mathrm{DS}=0.2 \mathrm{mg} \mathrm{mL}^{-1}$ ) exhibited the following properties: size of $151.2 \pm 1.4 \mathrm{~nm}$, PDI 0.293 , $\zeta=-42.1 \pm 0.6 \mathrm{mV}$, and $\mathrm{AE}=38.6 \pm 1.22 \%$.

TMC and COS behave differently when interacting with BVZ/DS nanoparticles (Fig. 5). At the lowest tested concentration, TMC reduced $\mathrm{AE} \%$ when compared to binary nanoparticles. From 0.1 to $0.2 \mathrm{mg} \mathrm{mL}^{-1}$, both TMC and COS promoted an increase in $\mathrm{AE} \%$ with increased polycation concentration. Furthermore, systems synthesized with $\mathrm{COS}$ demonstrated accentuated $\mathrm{AE} \%$ compared to those synthesized with TMC. For the highest evaluated concentrations, 0.4 and $0.6 \mathrm{mg} \mathrm{mL}^{-1}$, there was a drop off of $\mathrm{BVZ} \mathrm{AE} \%$ for both polycations, which can be explained by the competition with BVZ for the DS interaction sites. This competitive effect is more pronounced for TMC and can be unable to associate with BVZ when the polycation is at a concentration of $0.6 \mathrm{mg} \mathrm{mL}^{-1}$. In these conditions, the nanoparticles are, in fact, binary TMC/DS, and BVZ emerges in the dispersion medium. For $\mathrm{COS}$ in the range of $0.4-0.6 \mathrm{mg} \mathrm{mL}^{-1}, \mathrm{AE} \%$ reaches $73 \%$. The different interaction profile between COS and TMC may be attributed to molecular weight and carried charge density. TMC is a trimethylated chitosan with high molecular weight and is known for having high density of fixed positive charges. On the other hand, COS is a fragmented chitosan oligosaccharide which exhibits low molecular weight and charge density values.

\subsection{Interaction energy explains the different behaviors exhibited by TMC and $\operatorname{COS}$ when forming ternary systems}

Isothermal titration calorimetry derives thermodynamic information in order to elucidate the type of interaction that occurred at the molecular level. This technique is quite commonly explored in the area of molecular biophysics and it has recently been applied in the science of drug delivery systems, aiming to rationally design formulation development [41]. Here, supramolecular the interactions between the BVZ - DS, TMC - DS, and COS - DS pairs were studied in order to further substantiate the obtained results of $\mathrm{AE} \%$ as a function of the polycation types and concentrations. Thus, these experiments were conducted in an attempt to understand why the two types of chitosan (TMC and COS) act so differently when forming ternary nanoparticles.

ITC results of all interacting pairs suggested the occurrence of a single interaction and therefore the data were fit to the model of "one set of identical binding sites" (Fig. 6). Titrations showed negative peaks, indicating an exothermic interaction process. The extracted thermodynamic parameters are shown in the Table 2. Stoichiometry (n), the number of titrant molecules that bind to the one target molecule, was significantly different between the three pairs studied. COSDS showed the highest stoichiometry at all studied temperatures. COS molecular weight is approximately 23 times lower than that of TMC, which explains that more molecules are necessary for saturation of DS binding sites. Additionally, the COS-DS pair showed significant progressive reduction of $\mathrm{n}$ as temperature increased. This behavior was not observed for BVZ-DS and TMC-DS pairs, suggesting that the COS-DS interaction is temperature-dependent, which is possibly due to conformational changes.

The TMC - DS interaction showed the highest affinity constant (Ka), in the order of $10^{8} \mathrm{M}^{-1}$. For BVZ - DS and COS - DS pairs Ka was in the order of $10^{7} \mathrm{M}^{-1}$. Ka values suggest that both molecular weight and positive charge density of polycations are key factors that affect the interaction. The reduced values of the apparent Gibbs free energy change of all pairs studied characterized the spontaneity of the nanoparticle formation. TMC-DS showed larger negative values of free energy than the other pairs, exhibiting a more spontaneous assembly. Furthermore, enthalpy and entropy analyses showed that these interactions are guided by a favorable enthalpy factor, largely negative, for all studied pairs. Since entropy was negative, which represents a nonspontaneous system organization, the enthalpy factor was determined as the main contributor in the interaction and nanoparticle formation. All these thermodynamic data recap the same pattern observed in BVZ AE\% studies. Thus, TMC has a higher affinity with DS and is able to displace BVZ from its association with DS.

\subsection{Polycation concentration and theoretical solids content affect colloidal properties of ternary BVZ/ DS/ COS nanoparticles}

Our previous studies on the use of different polycations to form binary nanoparticles enabled us to select COS as the best polycation for producing ternary nanoparticles, since it ensured high rates of $\mathrm{AE} \%$ to the system. Thus, BVZ/DS/COS nanoparticles followed the same study methods as BVZ/DS nanoparticles. Initially, we investigated the behavior of colloidal properties according to different COS concentrations. Subsequently, the best protein: polyanion: polycation mass ratio was investigated against different solids content.

The colloidal properties of BVZ/DS/COS ternary nanoparticles were dependent on the polycation concentration (Fig. 7). The size of the particles gradually increased as COS increased, which is a result of higher association of the polycation with the system. PdI also increases progressively, starting at a low polydispersity $(\mathrm{PdI} \sim 0.2)$ and rising to a high level of polydispersity (PdI $>0.4$ ). Finally, ZP followed the same trend: values increased as COS concentration increased. Initially, in negative to low $\mathrm{COS}$ concentrations, $\mathrm{ZP}$ reached positive values ( $>40 \mathrm{mV}$ ) at 0.4 and $0.6 \mathrm{mg} \mathrm{mL}^{-1}$ of COS. These conditions reflect a situation where the polycation concentration is two times greater than the DS concentration, $0.2 \mathrm{mg} \mathrm{mL}^{-1}$.

The evaluation of colloidal properties of the ternary nanoparticles as function of the COS concentration indicated that 1.25:1:2 (protein: polyanion: polycation) was the best mass ratio formulation for producing ternary systems. Then, we evaluated how such properties behave as a function of solids content, defined in this case as the sum of the protein, polyanion, and polycation mass used to prepare $2 \mathrm{~mL}$ of ternary nanoparticles (Fig. 8). Size and PdI increased as solids content increased. Similar to the produced binary systems, a greater number of molecules were confined to the same volume and this could have intensified the supramolecular interactions. Increased ZP indicates that a higher degree of confinement promoted greater COS association for producing ternary systems. The BVZ AE\% was significantly higher in samples with solids content of $1.7 \mathrm{mg}$, compared to 0.85 and $3.4 \mathrm{mg}$.

As a result, in order to proceed with BVZ structural characterization and biological assessments, the best BVZ/DS/COS formulation was set 

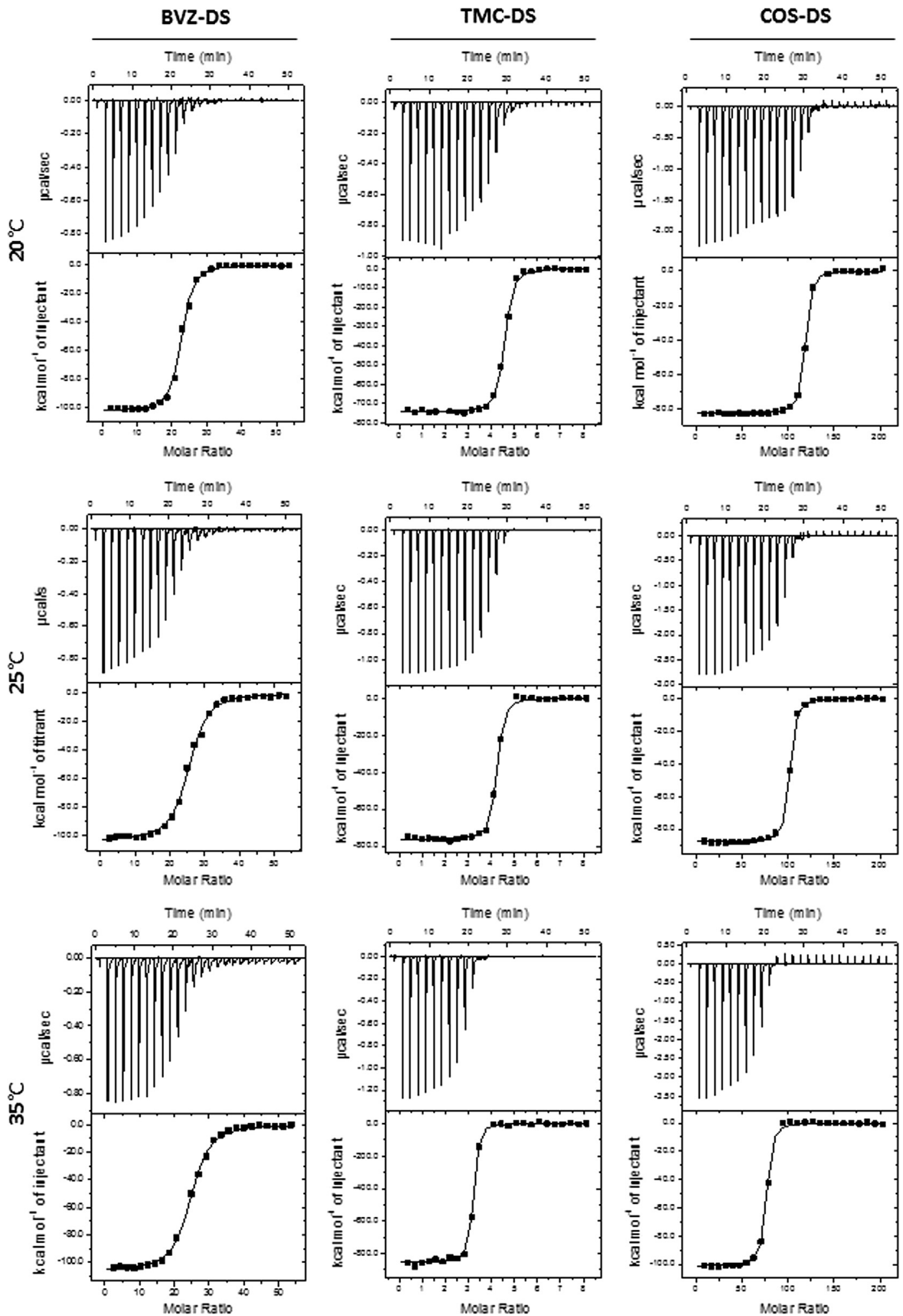

Fig. 6. ITC experimental data (upper graphs) and heat of injection (lower graphs) obtained by integration of the heat flow peaks as a function of protein-polyanion

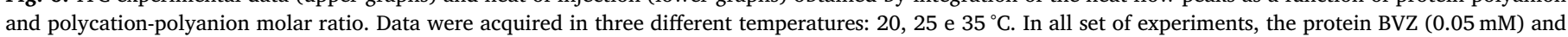
polycations TMC $(0.008 \mathrm{mM})$ and COS $(0.2 \mathrm{mM})$ were injected into a cell containing the polyanion DS $(0.0002 \mathrm{mM})$.

according to colloidal properties and $\mathrm{AE} \%$. The $\mathrm{BVZ} / \mathrm{DS} / \mathrm{COS}$ formulation chosen $\left(\mathrm{BVZ}=0.25 \mathrm{mg} \mathrm{mL}^{-1} \quad \mathrm{DS}=0.2 \mathrm{mg} \mathrm{mL}^{-1}\right.$ and $\operatorname{COS}=0.4 \mathrm{mg} \mathrm{mL}^{-1}$ ) exhibited the following characteristics: size $346 \pm 2 \mathrm{~nm}$, PDI $0.334, \zeta=+40.0 \pm 0.50 \mathrm{mV}$ and $\mathrm{AE}=73 \pm 2 \%$.

\subsection{BVZ exhibits different structural and thermal profiles in binary and ternary nanoparticles}

After defining the binary BVZ/DS and ternary BVZ/DS/COS nanoparticle compositions, we performed a biophysical characterization of 
Table 2

Temperature dependence of the thermodynamic parameters of protein-polyanion and polycation-polyanion binding determined by ITC.

\begin{tabular}{|c|c|c|c|c|c|c|}
\hline Sistema & $\mathrm{T}\left({ }^{\circ} \mathrm{C}\right)$ & $\mathrm{n}$ & Ka $\left(\mathrm{M}^{-1} \times 10^{-6}\right)$ & $\Delta \mathrm{H}\left(\mathrm{J} \mathrm{mol}^{-1} \times 10^{5}\right)$ & $\Delta \mathrm{S}\left(\mathrm{J} \mathrm{mol}^{-1} \mathrm{deg}^{-1} \times 10^{3}\right)$ & $\Delta \mathrm{G}\left(\mathrm{J} \mathrm{mol}^{-1} \times 10^{5}\right)$ \\
\hline \multirow[t]{3}{*}{ BVZ-DS } & 20 & 22 & $44 \pm 5$ & $-4.3 \pm 0.03$ & -1.3 & -3.4 \\
\hline & 25 & 25 & $18 \pm 2$ & $-4.4 \pm 0.04$ & -1.3 & -3.4 \\
\hline & 35 & 24 & $17 \pm 1$ & $-4.4 \pm 0.03$ & -1.3 & -3.5 \\
\hline \multirow[t]{3}{*}{ TMC-DS } & 20 & 4 & $810 \pm 90$ & $-31 \pm 0.14$ & -1.0 & -24 \\
\hline & 25 & 4 & $1000 \pm 100$ & $-32 \pm 0.16$ & -1.1 & -24 \\
\hline & 35 & 3 & $1500 \pm 200$ & $-36 \pm 0.15$ & -1.1 & -27 \\
\hline \multirow[t]{3}{*}{ COS-DS } & 20 & 115 & $63 \pm 5$ & $-3.5 \pm 0.01$ & -1.0 & -2.7 \\
\hline & 25 & 98 & $53 \pm 6$ & $-3.7 \pm 0.01$ & -1.1 & -2.9 \\
\hline & 35 & 73 & $40 \pm 5$ & $-4.2 \pm 0.02$ & -1.2 & -3.3 \\
\hline
\end{tabular}

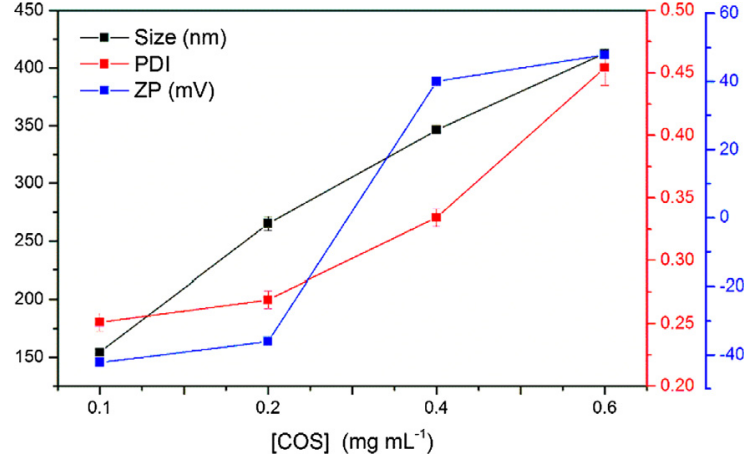

Fig. 7. Influence of polycation concentration on colloidal properties of BVZ/ DS / COS nanoparticles.

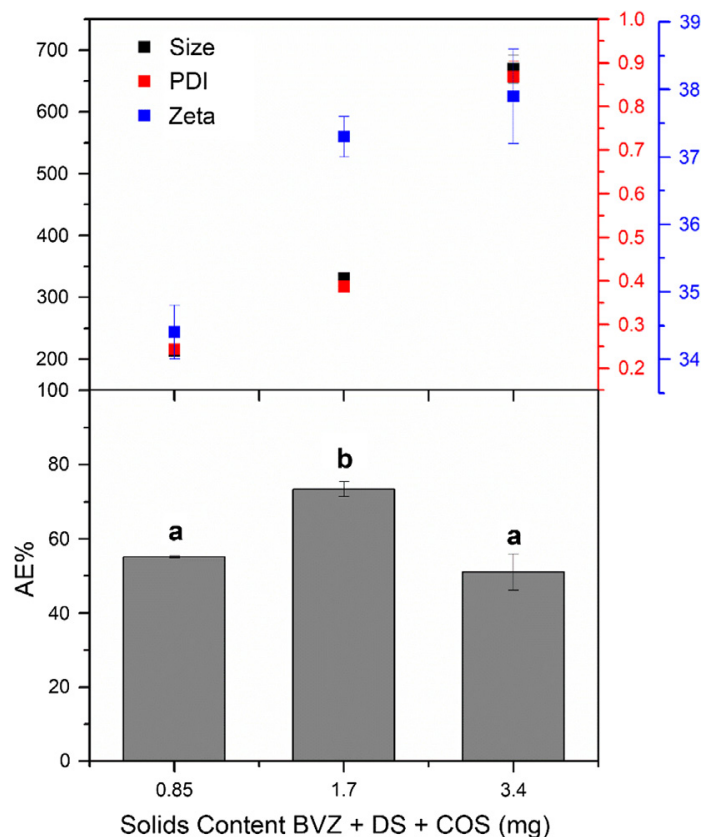

Fig. 8. Influence of solids content on colloidal properties of BVZ/DS/COS nanoparticles: size, polydispersity index (PDI), zeta Potential (ZP) and association efficiency (AE\%). Different letters demonstrate significant statistical differences $(\mathrm{p}<0.05)$.

BVZ when associated to each of these systems, while free BVZ was used as control. The CD spectra of free BVZ and BVZ associated to binary and ternary nanoparticles are virtually identical (Fig. 9A). When analyzing the secondary structure elements (Table 3 ), no changes were observed in the percentage of $\beta$ sheet-structure on BVZ incorporated into both types of particles. These results indicated that secondary and tertiary BVZ structures (evaluated by positive band at $230 \mathrm{~nm}$ ) are preserved in
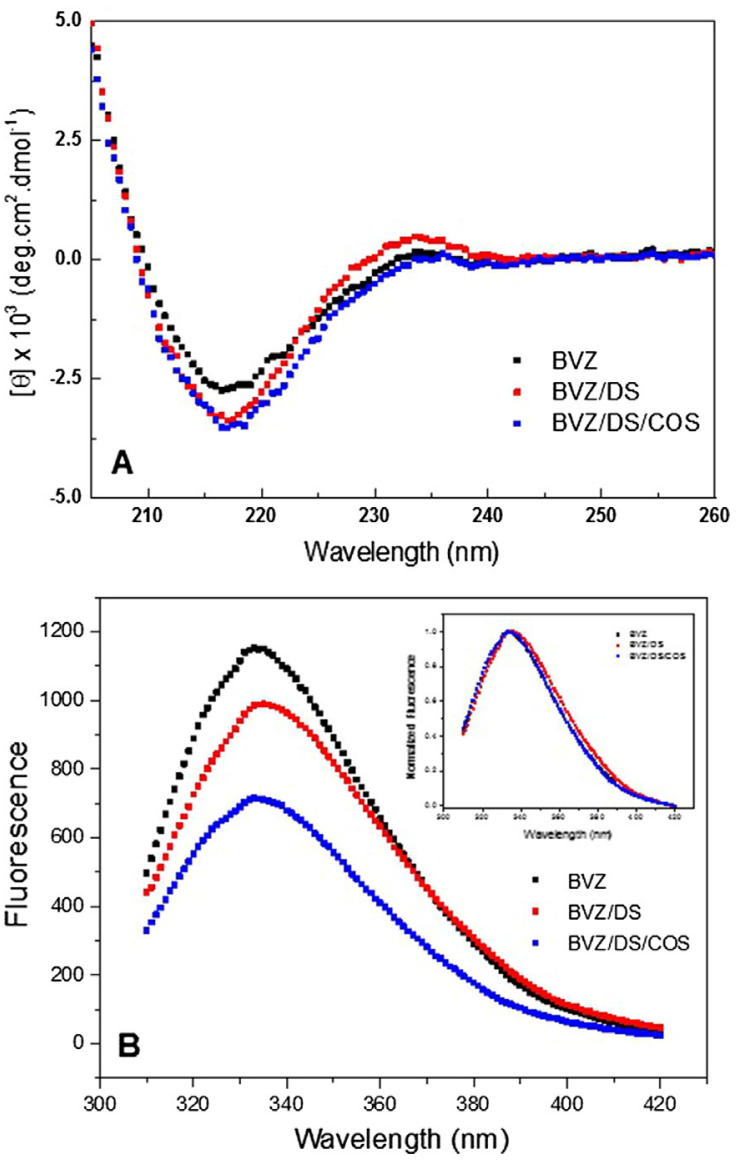

Fig. 9. (A) CD and (B) Fluorescence Spectroscopic Analysis of pure BVZ and BVZ in binary and ternary nanoparticles in PBS $5.1 \mathrm{mM} \mathrm{pH} \mathrm{6.2.}$

both formulations.

Intrinsic fluorescence spectra of tryptophan indicated progressive suppression of fluorescence in the following order: BVZ - BVZ/DS BVZ/DS/COS, which is related to environmental changes in amino acids (Fig. 9B). However, normalized inset graph demonstrated that the mean environment of tryptophans remains the same. From the analysis of $\lambda_{\max }$ and $\langle\lambda\rangle$, presented in Table 3 , we noticed a red shift $(\sim 2 \mathrm{~nm})$ in BVZ embedded in BVZ/DS nanoparticles, which may be related to tryptophan exposure. However, this observation was not noticed in BVZ/DS/COS nanoparticles, suggesting that adding the polycation induces the protein to return to its original conformation.

To deepen our understanding about BVZ structural features associated with binary and ternary nanoparticles, we conducted differential scanning microcalorimetry (Nano DSC). This highly sensitive technique characterizes the protein denaturing processes as well as the disruptions of interactions that maintain the integrity of nanostructured systems. In 
Table 3

Structural and calorimetric parameters of BVZ in binary BVZ/DS and ternary BVZ/DS/COS nanoparticles.

\begin{tabular}{|c|c|c|c|c|c|}
\hline \multirow[t]{2}{*}{ Technique } & & \multirow[t]{2}{*}{ Property } & \multicolumn{3}{|l|}{ Formulations } \\
\hline & & & BVZ & BVZ/DS & BVZ/DS/COS \\
\hline \multirow[t]{4}{*}{ CD } & & $\alpha$-helix (\%) & 5 & 5 & 6 \\
\hline & & $\beta$-sheet $(\%)$ & 47 & 47 & 46 \\
\hline & & $\beta$-turn (\%) & 16 & 17 & 16 \\
\hline & & Random & 35 & 35 & 35 \\
\hline \multirow[t]{3}{*}{ Fluorescence } & & $\lambda_{\max }(\mathrm{nm})$ & 333 & 335 & 333 \\
\hline & & $\langle\lambda\rangle(\mathrm{nm})$ & 345 & 347 & 345 \\
\hline & $1^{\circ}$ Event & $\mathrm{T}_{\mathrm{m}}\left({ }^{\circ} \mathrm{C}\right)$ & $73.5 \pm 1$ & - & 71.9 \\
\hline \multirow[t]{3}{*}{ Nano DSC } & $2^{\circ}$ Event & $\Delta \mathrm{H}\left(\mathrm{kJ} \mathrm{mol}^{-1}\right)$ & $2245 \pm 22.2$ & - & $1636 \pm 75.3$ \\
\hline & & $\mathrm{T}_{\mathrm{m}}\left({ }^{\circ} \mathrm{C}\right)$ & $85.3 \pm 1$ & - & $84.1 \pm 1$ \\
\hline & & $\Delta \mathrm{H}\left(\mathrm{kJ} \mathrm{mol}^{-1}\right)$ & $110.0 \pm 26.8$ & - & $86.82 \pm 23.4$ \\
\hline
\end{tabular}

fact, both the protein unfolding and breakdown of nanostructured selfassembled units can be considered complex processes, which are dependent on supramolecular interactions, such as hydrogen bonds, ionic interactions, hydrophobic bonds, and solvation effects. Thus, the presence of any other agent within the system may significantly stabilize or destabilize the delicate association.

Similar to other monoclonal antibodies, BVZ has a highly complex structure, which can be seen in its thermal profile (Fig. 10). The existence of multiple domains within the protein structure is responsible for the non-Gaussian behavior of BVZ thermal unfolding. The molecular "Y" structure of BVZ is enabled by the three-dimensional organization of two identical heavy and light chains. The three-dimensional structure is delimited into two distinct regions highly associated with the biological function of the protein: $\mathrm{F}_{\mathrm{ab}}$ (fragment antigen binding) and $\mathrm{F}_{\mathrm{c}}$ (fragment crystallizable). Thus, the structural integrity assessments should be evaluated after nanoparticle formation.

Basically, two thermal events were observed from the DSC analysis. The first thermal transition is centered at $\mathrm{T}_{\mathrm{m}}=73.5^{\circ} \mathrm{C}$ and can be attributed to the unfolding of the $\mathrm{F}_{\mathrm{ab}}$ fragment. The second transition is centered at $\mathrm{T}_{\mathrm{m}}=85.3^{\circ} \mathrm{C}$ and was attributed to the $\mathrm{F}_{\mathrm{c}}$ fragment (Table 3). These results are in agreement with thermal studies of immunoglobulins [42]. According to those studies, two domains suffered thermodenaturation under different conditions and by different mechanisms, which resulted in the appearance of two distinct endothermic peaks. Recent studies, focused on the immunoglobulin IgG1, demonstrating how each of these domains contribute to the stabilization of the three-dimensional structure. BVZ was used as immunoglobulin model and the thermal transitions were assigned based on calorimetric studies of antibody fragments, obtained by enzymatic digestion. Thus, the authors validated the two endothermic peaks at temperatures around 70

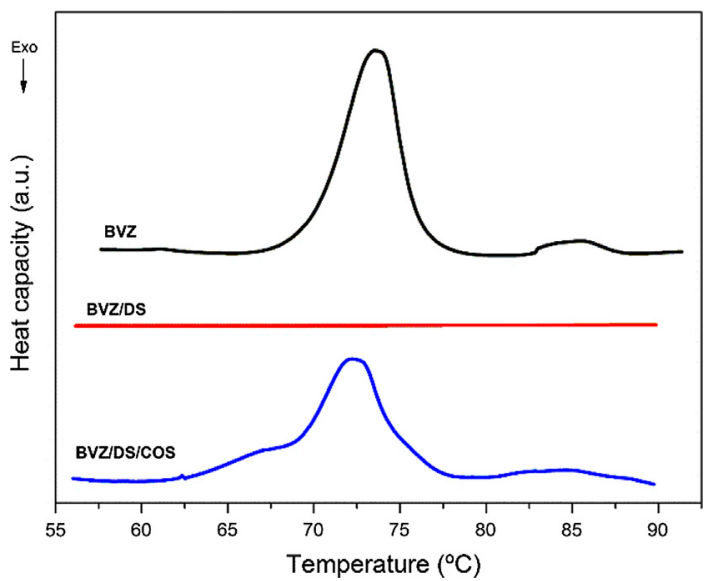

Fig. 10. Thermograms of pure BVZ, BVZ/DS and BVZ/DS/COS nanoparticles. $[\mathrm{BVZ}]=0.250 \mathrm{mg} \mathrm{mL}^{-1}$, PBS $5.1 \mathrm{mM} \mathrm{pH} 6.2$. and $80^{\circ} \mathrm{C}$ as transitions of $\mathrm{F}_{\mathrm{ab}}$ and $\mathrm{F}_{\mathrm{c}}$, respectively [43]. Therefore, the thermal characterization of BVZ performed in our studies is in full agreement with the already reported results.

Since the BVZ thermal denaturation events were characterized, we used them as probes to monitor the changes in the antibody after their association with nanoparticles. BVZ embedded in BVZ/DS nanoparticles exhibited no thermal event, highlighting the strong interaction between protein and polyanion. All things considered, two hypotheses can be formulated: first, DS completely denatured BVZ and consequently no event indicating this process could be detected, or, second, the event increased to a very high temperature, superior to the detection range of the equipment $\left(>100^{\circ} \mathrm{C}\right)$. In the latter, DS would have acted as a thermostabilizing agent. As previously shown in our CD and fluorescence results, BVZ maintained its three-dimensional structure, which supports the second hypothesis. Several studies have pointed out the stabilizing nature of polyanions on protein structures [44-46]. Recently, chitosan-DS nanoparticles were produced to encapsulate VEGF. VEGF-DS nanocomplexes showed no thermal denaturation events in the studied temperature, evidencing the stabilizing effect of the DS polyanion [47]. In another study, Chung and collaborators described how DS could prevent heat-induced protein aggregation. The combination of DS and bovine serum albumin (BSA) in nanocomplexes produced significant changes in the protein thermal stability. Calorimetric data obtained by ITC evidenced strong electrostatic attraction between DS and BSA, yielding a partially denatured state, which prevents the aggregation.

The thermogram of BVZ embedded in the ternary nanoparticles (BVZ/DS/COS) returned to the same profile demonstrated by pure BVZ and showed two main events at $\mathrm{T}_{\mathrm{m}}=71.9^{\circ} \mathrm{C}$ and $\mathrm{T}_{\mathrm{m}}=84.1^{\circ} \mathrm{C}$. In addition, during the first event, concerning the $\mathrm{F}_{\mathrm{ab}}$ segment, an unfolding event occurred at a temperature below $70^{\circ} \mathrm{C}$. Enthalpy also showed a significant drop off, suggesting increased flexibility in the $\mathrm{F}_{\mathrm{ab}}$ subunit.

\subsection{BVZ remains functional after being incorporated by nanoparticles}

BVZ secondary and tertiary structures are preserved after the protein is incorporated into nanoparticles, as evidenced by spectroscopic and calorimetric experiments. However, the present study aimed to also investigate how this event reflects in its biological function. We evaluated this matter with the assistance of the CAM assay, which is commonly used to evaluate the pro and anti-angiogenic activities of drugs [48]. Results demonstrated that all groups had a reduced number of blood vessels when compared with the control (Fig. 11). Pure BVZ blocked the formation of new blood vessels, as expected, but after incorporation into binary and ternary nanoparticle, a more accentuated reduction was observed. Additionally, its incorporation into ternary nanoparticles seemed to positively affect the biological function of BVZ in the angiogenesis processes since a constant reduction of the number 


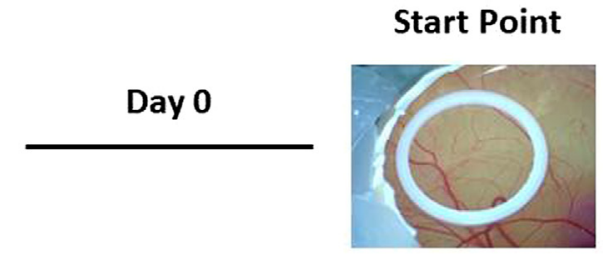

Control (PBS)

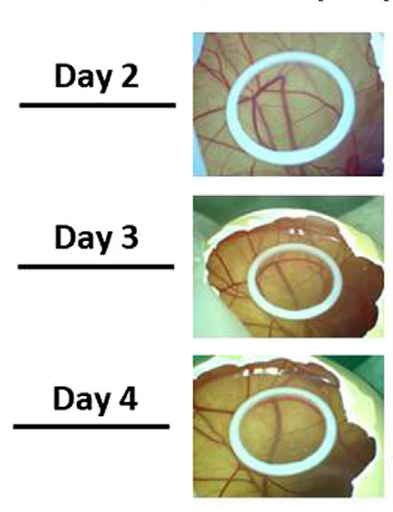

BVZ

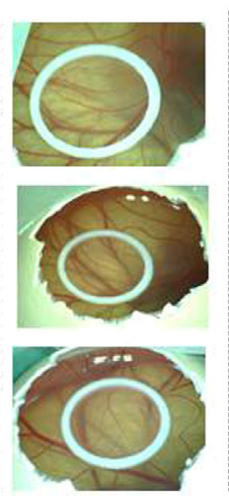

DS

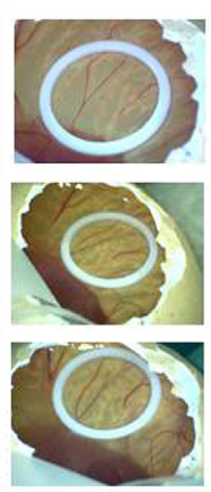

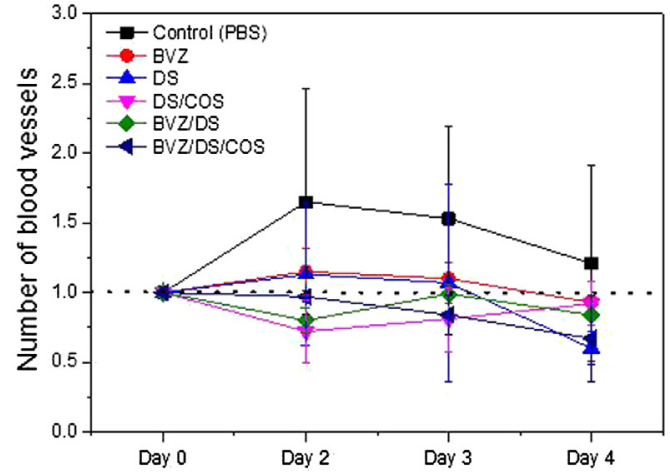

DS/COS

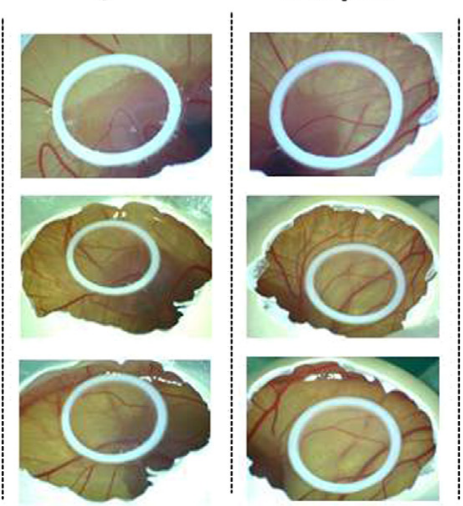

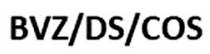

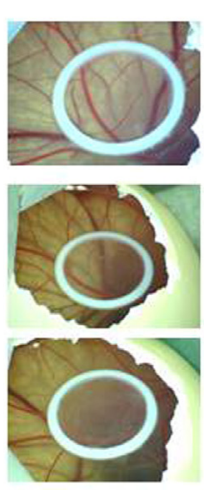

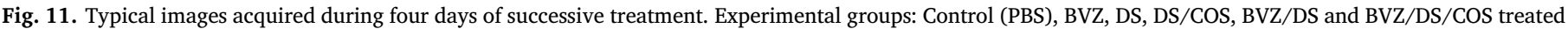
with $100 \mu \mathrm{L}$ formulation on a daily basis.
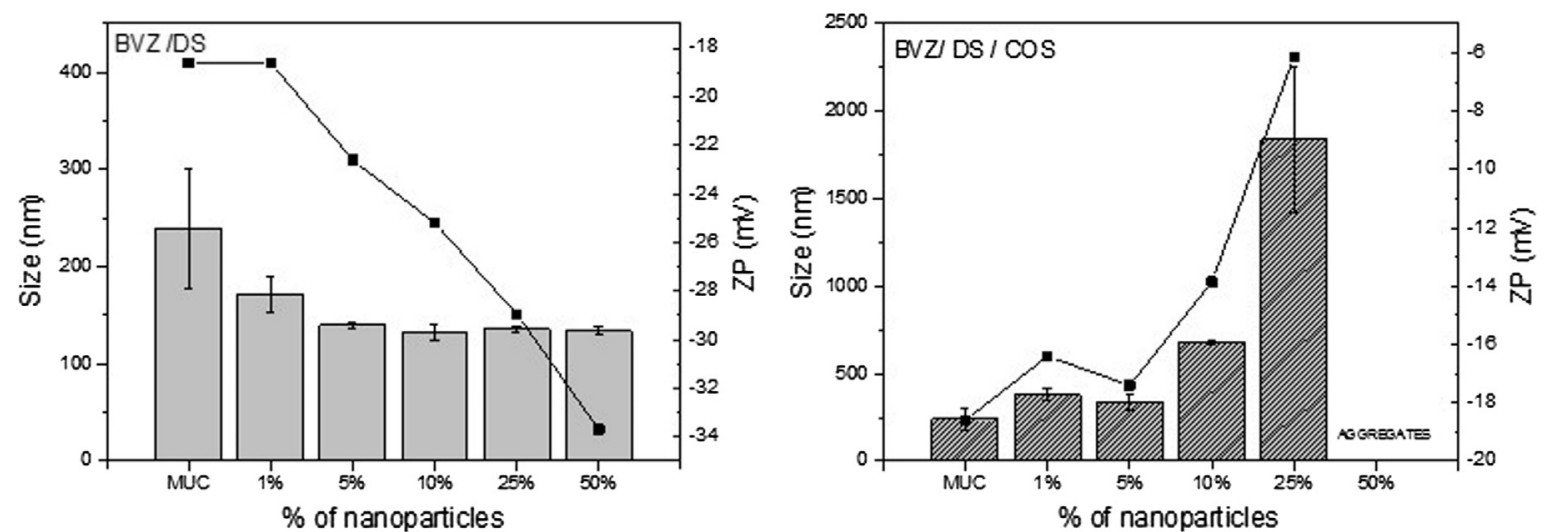

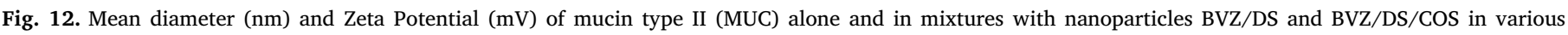
proportions.

of blood vessels was observed over time. In the images corresponding to Day 4, there were no vessels inside the Teflon $^{\circledast}$ ring for this group, showing consistent results between the quantitative and qualitative analyses. This indicates that BVZ/DS/COS nanoparticles hinder not only the formation of new blood vessels but also destroy the existing vessels. Furthermore, even the DS polymer showed an anti-angiogenic effect, which can be related to other VEGF-related mechanisms of angiogenesis [49].

\subsection{Binary and ternary nanoparticles show opposite behavior when interacting with mucin}

Mucins constitute the basic unit responsible for mucus structure and function and, therefore, were used in DLS and ZP experiments to evaluate its interaction with previously developed binary and ternary nanoparticles [50]. The mucin particle method exhibits the colloidal behavior of mucin-mucin aggregates in relation to the addition of polymers and/or drug delivery systems [51,52]. We observed that the interaction profile of binary and ternary nanoparticles exhibited opposite behavior (Fig. 12). The size of mucin aggregates and the ZP values decreased as the concentration of BVZ/DS nanoparticles increased. BVZ/DS/COS nanoparticles formed insoluble aggregates (naked eye viewing) because of charge neutralization. Recently, some studies have reported the mucus penetrating function of polyanions and negatively charged nanoparticles [53,54]. Furthermore, some studies have reported that the DS polyanion can change mucus thickness and the dynamic of mucins $[29,55]$. However, they were unable to affirm whether this effect is specific or nonspecific. On the other hand, the chitosan ability to act as a mucoadhesive agent is well known and corroborated with the present results. 

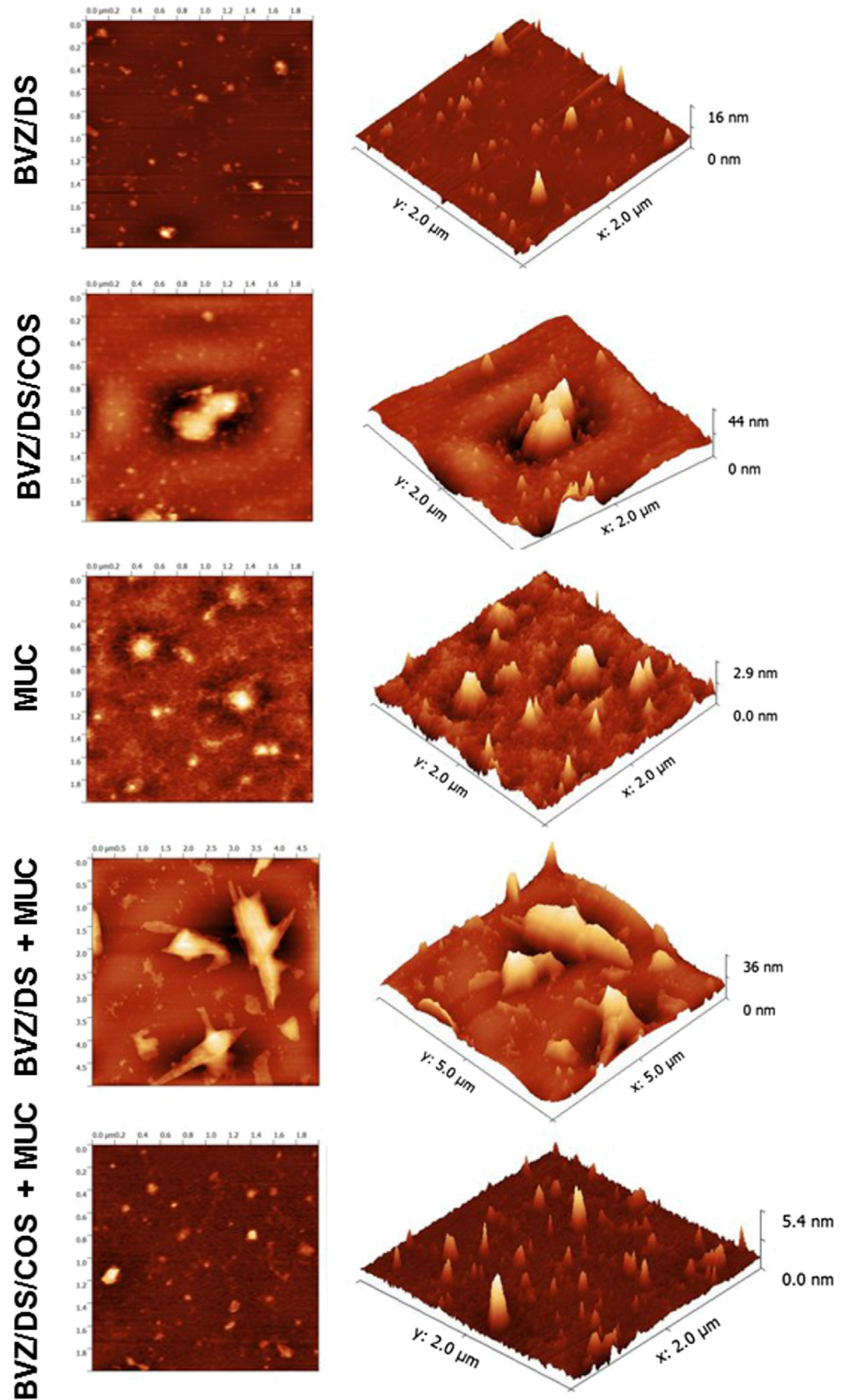

Fig. 13. AFM topographic images acquired for binary and ternary nanoparticles interacting with mucin.

To better understand the differences between the interaction profiles of mucin and the produced nanoparticles, AFM studies were performed. This technique has been widely used not only to characterize nanoparticulate systems, but also to further understand, in nanoscale, their complex interaction processes with biological systems [56]. 2D and 3D images of nanoparticles, pure mucin, and the combination of both can be seen in Fig. 13. BVZ/DS binary nanoparticles are smaller than the ternary BVZ/DS/COS. Furthermore, ternary nanoparticles are prone to aggregation. The non-directional nature of electrostatic interactions may be responsible for the formation of such clusters since it may be acting as a bridge between two particles. The mucin appears to be densely packed and exhibits a very irregular topography. Punctual differences could be seen in the interactions between nanoparticles and mucin, such as BVZ/DS + MUC showed a dispersed network, while BVZ/DS/COS + MUC exhibited several aggregation points. 


\section{Conclusions}

We successfully designed two types of polymer-based nanoparticles combining mucous penetrating and mucoadhesive materials. Using a combination of scattering, spectroscopic and calorimetric techniques, we were able to rationalize the development process of the delivery systems by manipulating supramolecular interactions between three classes of building blocks: protein, polycation and polyanion. The concentration of polyanion and polycation and the total solids content affected the properties of the nanoparticles. Binary nanoparticles, composed of the DS polyanion and the BVZ protein, exhibited a size of approximately $150 \mathrm{~nm}$ and negative ZP. Furthermore, when interacting with mucin, they possibly disrupted mucin-mucin interactions due to their mucus penetrating effect. The ternary nanoparticles with residual positive charge were developed through a detailed thermodynamic characterization, aiming to understand the process of supramolecular interactions among the building blocks. This assessment enabled us to select COS over TMC, when producing protein-polyanion-polycation nanoparticles. These particles exhibited a size of approximately $350 \mathrm{~nm}$, positive charge, and aggregates in the presence of mucin, which was possibly due to their mucoadhesive activity. Additionally, BVZ had its structure and function preserved as evidenced by CD, fluorescence spectroscopy, and CAM assay. All things considered, these findings suggest that supramolecular interactions can be manipulated to produce bevacizumab drug-delivery prototypes, which might exhibit opposite behaviors in mucosal environment. We anticipate here that the same rationale could be applied for similar mAbs, aiming to develop platform technologies for potential mucosal delivery. Finally, investigations should be conducted to adjust properties and modulate mucus/nanocarrier interactions, improving mucoadhesion or penetration and system performance when administered.

\section{Conflicts of interest}

The authors declare no competing financial interests.

\section{Author contributions}

The manuscript was composed by contributions of all authors. All authors have approved of the final version of this manuscript.

\section{Acknowledgment}

This work was financianced by Fundação de Amparo e Pesquisa do Estado de São Paulo (FAPESP Process n. 2012/13446-4; 2012/10174-3; 2016/09671-3 and 2017/16324-0), Brazilian National Institute for Science and Technology (INCT Process n. 2014/50928) and PADC (Programa de Apoio ao Desenvolvimento Científico)-FCF-UNESP. The authors would like to thank Dr. Rubens Bernardes Filho (Embrapa São Carlos) for his assistance with AFM images and Professor Vanderlei Salvador Bagnato (IFSC/USP) allowing the use of the laboratory.

\section{References}

[1] J.G. Elvin, R.G. Couston, C.F. van der Walle, Therapeutic antibodies: Market considerations, disease targets and bioprocessing, Int. J. Pharm. 440 (1) (2013) 83-98.

[2] D.M. Ecker, S.D. Jones, H.L. Levine, The therapeutic monoclonal antibody market, mAbs 7(1) (2015) pp. 9-14.

[3] Z. Rosman, Y. Shoenfeld, G. Zandman-Goddard, Biologic therapy for autoimmune diseases: an update, Bmc Med. 11 (2013) 88-88.

[4] L. Bossaller, A. Rothe, Monoclonal antibody treatments for rheumatoid arthritis, Expert Opin. Biol. Ther. 13 (9) (2013) 1257-1272.

[5] A.M. Scott, J.D. Wolchok, L.J. Old, Antibody therapy of cancer, Nat. Rev. Cancer 12 (4) (2012) 278-287.

[6] D. Tarabar, A. Hirsch, D.T. Rubin, Vedolizumab in the treatment of Crohn's disease, Expert Rev. Gastroenterol. Hepatol. 10 (3) (2016) 283-290.

[7] A. Maillet, L. Guilleminault, E. Lemarie, S. Lerondel, N. Azzopardi, J. Montharu, N. Congy-Jolivet, P. Reverdiau, B. Legrain, C. Parent, D.H. Douvin, J. Hureaux, Y. Courty, M. De Monte, P. Diot, G. Paintaud, A. Le Pape, H. Watier, N. Heuze-
Vourc'h, The Airways, a novel route for delivering monoclonal antibodies to treat lung tumors, Pharm. Res. 28 (9) (2011) 2147-2156.

[8] Y.-C. Kim, B. Chiang, X. Wu, M.R. Prausnitz, Ocular delivery of macromolecules, J. Control. Release 28 (2014) 172-181.

[9] J.B. Gunther, M.M. Altaweel, Bevacizumab (Avastin) for the treatment of ocular disease, Surv. Ophthalmol. 54 (3) (2009) 372-400.

[10] S. Mitragotri, P.A. Burke, R. Langer, Overcoming the challenges in administering biopharmaceuticals: formulation and delivery strategies, Nat. Rev. Drug Discov. 13 (9) (2014) 655-672.

[11] N. Ferrara, K.J. Hillan, W. Novotny, Bevacizumab (Avastin), a humanized antiVEGF monoclonal antibody for cancer therapy, Biochem. Biophys. Res. Commun. 333 (2) (2005) 328-335.

[12] D. Park, V. Shah, B.M. Rauck, T.R. Friberg, Y. Wang, An anti-angiogenic reverse thermal gel as a drug-delivery system for age-related wet macular degeneration, Macromol. Biosci. 13 (4) (2013) 464-469.

[13] G. Samson, A. Garcia de la Calera, S. Dupuis-Girod, F. Faure, E. Decullier, G. Paintaud, C. Vignault, J.Y. Scoazec, C. Pivot, H. Plauchu, F. Pirot, Ex vivo study of bevacizumab transport through porcine nasal mucosa, Eur. J. Pharm. Biopharm. 80 (2) (2012) 465-469.

[14] A.B. Thompson, D.A. Ross, P. Berard, J. Figueroa-Bodine, N. Livada, S.L. Richer, Very low dose bevacizumab for the treatment of epistaxis in patients with hereditary hemorrhagic telangiectasia, AllergyRhinol. (Providence) 5 (2) (2014) e91-e95.

[15] F. Laffleur, F. Hintzen, G. Shahnaz, D. Rahmat, K. Leithner, A. Bernkop-Schnurch, Development and in vitro evaluation of slippery nanoparticles for enhanced diffusion through native mucus, Nanomedicine (Lond) 9 (3) (2013) 387-396.

[16] J.D. Smart, The basics and underlying mechanisms of mucoadhesion, Adv. Drug Deliv. Rev. 57 (11) (2005) 1556-1568.

[17] Y.Y. Wang, S.K. Lai, J.S. Suk, A. Pace, R. Cone, J. Hanes, Addressing the PEG mucoadhesivity paradox to engineer nanoparticles that "slip" through the human mucus barrier, Angew. Chem. 47 (50) (2008) 9726-9729.

[18] K. Maisel, L. Ensign, M. Reddy, R. Cone, J. Hanes, Effect of surface chemistry on nanoparticle interaction with gastrointestinal mucus and distribution in the gastrointestinal tract following oral and rectal administration in the mouse, J. Control Release 197 (2015) 48-57.

[19] P. Schattling, E. Taipaleenmaki, Y. Zhang, B. Stadler, A. Polymer, Chemistry point of view on mucoadhesion and mucopenetration, Macromol. Biosci. 17 (9) (2017).

[20] I. Lynch, I.L. Feitshans, M. Kendall, 'Bio-nano interactions: new tools, insights and impacts': summary of the Royal Society discussion meeting, Philos. Trans. R. Soc. Lond. B. Biol. Sci. 370 (1661) (2015) 20140162.

[21] J.V.D. Gucht, E. Spruijt, M. Lemmers, M.A. Cohen Stuart, Polyelectrolyte complexes: Bulk phases and colloidal systems, J Colloid Interface Sci. 361 (2) (2011) 407-422.

[22] M. Berry, A.P. Corfield, T.J. McMaster, Mucins: a dynamic biology, Soft Matter 9 (6) (2013) 1740.

[23] P. Verdugo, Supramolecular Dynamics of Mucus, Cold. Spring Harb. Perspect. Med. 2(11) (2012).

[24] W. Wang, S. Singh, D.L. Zeng, K. King, S. Nema, Antibody structure, instability, and formulation, J. Pharm. Sci. 96 (1) (2007) 1-26.

[25] F.I. Boni, A. Almeida, A. Lechanteur, B. Sarmento, B.S.F. Cury, M.P.D. Gremião, Mucoadhesive nanostructured polyelectrolytes complexes modulate the intestinal permeability of methotrexate, Eur. J. Pharm. Sci. 111 (2018) 73-82.

[26] F.G. Prezotti, F.I. Boni, N.N. Ferreira, S.P. Campana-Filho, A. Almeida, T. Vasconcelos, M.P.D. Gremião, B.S.F. Cury, B. Sarmento, Gellan gum/pectin beads are safe and efficient for the targeted colonic delivery of resveratrol, Polymers 10 (1) (2018) 50-64.

[27] P. Jakubiak, L.N. Thwala, A. Cadete, V. Préat, M.J. Alonso, A. Beloqui, N. Csaba, Solvent-free protamine nanocapsules as carriers for mucosal delivery of therapeutics, Eur. Polym. J. 93 (2017) 695-705.

[28] M.E.V. Johansson, J.K. Gustafsson, J. Holmén-Larsson, K.S. Jabbar, L. Xia, H. Xu, F.K. Ghishan, F.A. Carvalho, A.T. Gewirtz, H. Sjövall, G.C. Hansson, Bacteria penetrate the normally impenetrable inner colon mucus layer in both murine colitis models and patients with ulcerative colitis, Gut 63 (2) (2014) 281-291.

[29] M.E.V. Johansson, J.K. Gustafsson, K.E. Sjöberg, J. Petersson, L. Holm, H. Sjövall, G.C. Hansson, Bacteria penetrate the inner mucus layer before inflammation in the dextran sulfate colitis model, Plos One 5 (8) (2010) e12238.

[30] C. He, L. Yin, C. Tang, C. Yin, Size-dependent absorption mechanism of polymeric nanoparticles for oral delivery of protein drugs, Biomaterials 33 (33) (2012) 8569-8578.

[31] A. Jintapattanakit, V.B. Junyaprasert, T. Kissel, The role of mucoadhesion of trimethyl chitosan and PEGylated trimethyl chitosan nanocomplexes in insulin uptake, J. Pharm. Sci. 98 (12) (2009) 4818-4830.

[32] D. de Britto, O.B.G. Assis, A novel method for obtaining a quaternary salt of chitosan, Carbohyd. Polym. 69 (2) (2007) 305-310.

[33] G. Bohm, R. Muhr, R. Jaenicke, Quantitative-analysis of protein far UV circulardichroism spectra by neural networks, Protein Eng. 5 (3) (1992) 191-195.

[34] M.A. Cohen Stuart, Supramolecular perspectives in colloid science, Colloid \& Polymer Sci. 286(8) (2008) pp. 855-864.

[35] C. Tros de Ilarduya, Y. Sun, N. Duzgunes, Gene delivery by lipoplexes and polyplexes, Eur. J. Pharm. Sci. 40 (3) (2010) 159-170.

[36] P. Kos, U. Lächelt, D. He, Y. Nie, Z. Gu, E. Wagner, Dual-Targeted Polyplexes Based on Sequence-Defined Peptide-PEG-Oligoamino Amides, J. Pharm. Pharm. Sci. 104 (2) (2015) 464-475.

[37] K.S. Harve, M. Raghunath, R.R. Lareu, R. Rajagopalan, Macromolecular crowding in biological systems: dynamic light scattering (dls) to quantify the excluded volume effect (eve), Biophys. Rev. Lett. 01 (03) (2006) 317-325.

[38] P. Tyagi, M. Barros, J.W. Stansbury, U.B. Kompella, Light activated, in situ forming 
gel for sustained suprachoroidal delivery of bevacizumab, Mol. Pharm. 10 (2013) $2858-2867$.

[39] S.K. Yandrapu, A.K. Upadhyay, J.M. Petrash, U.B. Kompella, Nanoparticles in porous microparticles prepared by supercritical infusion and pressure quench technology for sustained delivery of bevacizumab, Mol. Pharm. 10 (12) (2013) $4676-4686$.

[40] T.V. Seraphim, L.M. Gava, D.Z. Mokry, T.C. Cagliari, L.R.S. Barbosa, C.H.I. Ramos, J.C. Borges, The C-terminal region of the human p23 chaperone modulates its structure and function, Arch. Biochem. Biophys. 565 (2015) 57-67.

[41] K. Bouchemal, New challenges for pharmaceutical formulations and drug delivery systems characterization using isothermal titration calorimetry, Drug. Discov. Today 13 (21-22) (2008) 960-972.

[42] A.W.P. Vermeer, W. Norde, The thermal stability of immunoglobulin: unfolding and aggregation of a multi-domain protein, Biophys. J. 78 (1) (2000) 394-404.

[43] R.M. Ionescu, J. Vlasak, C. Price, M. Kirchmeier, Contribution of variable domains to the stability of humanized IgG1 monoclonal antibodies, J. Pharm. Sci. 97 (4) (2008) 1414-1426.

[44] Olga N. Ivinova, V.A. Izumrudov, Vladimir I. Muronetz, Igor Yu Galaev, Bo Mattiasson, Influence of complexing polyanions on the thermostability of basic proteins, Macromol. Biosci. 3 (2003) 210-215.

[45] S.N.V. Haihong Fan, Tracy Chen, Donald O'Keefe, C. Russell Middaugh, Effects of $\mathrm{pH}$ and polyanions on the thermal stability of FGF20, Mol. Pharm. 4 (2) (2007) 232-240.

[46] T. Derrick, A.O. Grillo, S.N. Vitharana, L. Jones, J. Rexroad, A. Shah, M. Perkins, T.M. Spitznagel, C.R. Middaugh, Effect of polyanions on the structure and stability of repifermin (keratinocyte growth factor-2), J. Pharm. Sci. 96 (4) (2007) 761-776.

[47] M. Huang, S.N. Vitharana, L.J. Peek, T. Coop, C. Berkland, Polyelectrolyte complexes stabilize and controllably release vascular endothelial growth factor, Biomacromolecules 8 (5) (2007) 1607-1614.
[48] C. Storgard, D. Mikolon, D.G. Stupack, Angiogenesis assays in the chick CAM, in: J.-.L. Guan (Ed.), Cell Migration: Developmental Methods and Protocols, Humana Press, Totowa, NJ, 2005, pp. 123-136.

[49] M. Narazaki, M. Segarra, G. Tosato, Sulfated polysaccharides identified as inducers of neuropilin-1 internalization and functional inhibition of VEGF165 and semaphorin3A, Blood 111 (8) (2008) 4126-4136.

[50] R. Bansil, E. Stanley, J.T. LaMont, Mucin biophysics, Annu. Rev. Physiol. 57 (1995) 635-657.

[51] P. Sriamornsak, N. Wattanakorn, H. Takeuchi, Study on the mucoadhesion mechanism of pectin by atomic force microscopy and mucin-particle method, Carbohyd. Polym. 79 (1) (2010) 54-59.

[52] J. Thongborisute, H. Takeuchi, Evaluation of mucoadhesiveness of polymers by BIACORE method and mucin-particle method, Int. J. Pharm. 354 (1-2) (2008) 204-209.

[53] E.Y. Chen, D. Daley, Y.-C. Wang, M. Garnica, C.-S. Chen, W.-C. Chin, Functionalized carboxyl nanoparticles enhance mucus dispersion and hydration, Sci. Rep. 2 (2012) 211.

[54] M.F. Pritchard, L.C. Powell, G.E. Menzies, P.D. Lewis, K. Hawkins, C. Wright, I. Doull, T.R. Walsh, E. Onsøyen, A. Dessen, R. Myrvold, P.D. Rye, A.H. Myrset, H.N.E. Stevens, L.A. Hodges, G. MacGregor, J.B. Neilly, K.E. Hill, D.W. Thomas, A new class of safe oligosaccharide polymer therapy to modify the mucus barrier of chronic respiratory disease, Mol. Pharm. 13 (3) (2016) 863-872.

[55] M. Faure, D. Moënnoz, F. Montigon, C. Mettraux, S. Mercier, E.J. Schiffrin, C. Obled, D. Breuillé, J. Boza, Mucin production and composition is altered in dextran sulfate sodium-induced colitis in rats, Dig. Dis. Sci. 48 (7) (2003) 1366-1373.

[56] B.C. Zhenning Hong, Rama Bansil, Bradley S. Turner, K. Ramakrishnan Bhaskar, Nezam H. Afdhal, Atomic Force Microscopy reveals aggregation of gastric mucin at low pH, Biomacromolecules 6(6), pp. 3458-3466. 